\title{
Survey of Urban Spatial Quality Research under New Data and New Technology Environment
}

\author{
Ye Yang ${ }^{1,2}$, Jia Chaozhi ${ }^{1,2}$, Meng Xue ${ }^{1,2}$ \\ 1.School of Architecture, Harbin Institute of Technology, China \\ 2.Key Laboratory of Cold Region Urban and Rural Human Settlement Environment Science and \\ Technology, Ministry of Industry and Information Technology, China
}

\begin{abstract}
Urban space is an important part of people's life, and its spatial quality is essential to people's activities and behaviors. The emerging new data and new technologies improve traditional research methods in urban space significantly. This paper reviews, analyzes and summarizes new data and new technologies that have emerged in recent years, including build environment data, social media data, trajectory data, deep learning, virtual reality, eye tracking, and physiological sensor. This paper also analyzes the possibility of more precise analysis and more intuitive presentation of these new data and new technologies in urban spatial research methods. Finally, we propose a framework to response the possible application of these new data and new technologies in the process of urbanization.
\end{abstract}

\section{Keywords}

New data, new technology, urban spatial quality

\section{The development process of urban spatial quality research}

The development process of urban public space quality often goes through the stage of high speed to high quality. Since the urbanization process enters high quality development period, researchers are increasingly encouraged to take up more human-oriented approaches to meet people's demand, and the core value of urban design shifts away from object-oriented towards human-oriented. Hence, urban progress needs to utilize the potentials of new tools for not only more efficient analysis and visualizations, but also new research perspectives based on spatial design and perception.

The quality of the urban built environment has been extensively explored from multiple fields. Early researchers such as Kevien Lynch, Jane Jacobs set humanistic as the main topic in urban practice, which concentrates more on people's emotional feelings towards urban space. Allan B. Jacob paid more attention on urban space, in which people's pursuit of suitable environment had greatly promoted the activities. Then, several simple frameworks to analyze the qualities of public space were proposed, and various viewpoints focused on the quality of urban space to summarize high-quality urban space design (Van Kamp et al., 2003). With the development of the urbanization, researchers began to widely use models to study the urban built environment, detailedly address urban quality dimensions, indicators, and applied fields in their measurement tools and methods. These methods and tools obtained first-hand data which were collected in person emphasizing that urban design and built environments can be 
quantitatively measured (Cervero and Kockelman, 1997, Ewing et al., 2006). The urban model focused on different characteristics of the urban environment for different issues, and integrate urban street material space indicators in different aspects. At the same time, Some regions developed measurement tools to assess the quality of pedestrian environment, such as Systematic Pedestrian and Cycling Environment Scan(Pikora et al., 2002), Microscale Audit of Pedestrian Streetscapes(Millstein et al., 2013) and Pedestrian Environment Data Scan(Clifton et al., 2007), among the measurement tools, the content settings were detailed, helped designers to increase the quality of research effectively. However, due to the data collected through first-hand field observation, surveys, and interviews in urban space, to ensure the reliability of these measures and data in generating such tools is a complex and hard task (Mehta, 2014), and there is urgent need for easily obtained data and operated tool in urban research. In recent years, with the development of the network technology, huge amounts of data related to the urban environment and activities are emerging, a series of new research methods having also been developed to expend the understanding about urban spatial quality.

\section{New Data environment provides support for multi-scale urban spatial quantization and perception}

New data reflecting environmental characteristics and people's behavior is in line with the current urban development direction and has great impact on urban development. New data such as urban built environment data, social media data, and trajectory data have contributed to the formation of the new data environment, and show great support for urban spatial quantization and perception.

Urban built environment data is the basis of urban research. The massive data such as open-source platform data, point of interest (POI), and street view image (SVI), quantitatively grasp the various physical and spatial environmental characteristics of the city. Unlike traditional data, the open-source map platform, the so-called volunteered geographic information (VGI) platform, covers multiple basic data such as road networks and building outlines, and has the advantages of open editing, such as Open Street Map (OSM) (Haklay, 2010, Geiß et al., 2017). POI reflects format information in various regions of the city and has the advantage of data mining based on spatial location (Hu et al., 2020, Chen et al., 2020, Shi et al., 2021). SVI has a wide coverage and detailed illustration of urban street, intuitively reflects the urban façade information, and has the advantage of lower cost than on-site data collection, provide a large sample data source and new research ideas for urban environmental assessment. SVI is more focused on recording the stereoscopic sectional view of the street level from the perspective of people, which can represent scenes seen or felt from the ground on a fine scale, so it is suitable to replace on-site observation of urban environmental assessment and perception (Zhang et al., 2019). Researchers in recent years apply deep learning to SVI analysis, objectively measure the micro-elements of the built environment, including urban visual space indicators (Dai et al., 2021), cycling environment (Gullón et al., 2015), street safety (He et al., 2017), street disorder (Marco et al., 2017), street greening (Long and Liu, 2017), etc. With the trend of smart city construction, various professional institutions and platforms have also begun to share information and data, and actively integrate them into the common system, which relies on the new generation of information technology such as cloud computing and the Internet of Things, combined with real-time perceived information (Fang et al., 2021).

Social media big data include open platform data such as Twitter, Weibo, Flicker, etc. The platform is based on the comments posted by users to abundant data samples (Yang et al., 2021). It's essential to provide a better foundation for design and improve the everyday spaces of people by understanding people's experience of urban public space on social media (Kim et al., 2018). Based on open sharing of location, images, and text via social media, the real-time information carrying user's emotions and feelings reveal how humans think or act regardless of time or space (Wen and Wei, 2016). Moreover, 
new technologies have also been applied in researches which reveal hidden spatial issues in large amounts of data (Song et al., 2020, Wakamiya et al., 2015, Hu et al., 2015).

Trajectory data includes vehicle GPS records, mobile phone data (MPD), location-based service data (LBS), and mobile app data, covers the interaction between people and the social environment. Human activity trajectory data show valuable information on how urban spaces used in people's daily life (Hu et al., 2021). In addition, trajectory data can improve efficiency and possibility for planers to enhance public participation in local governance (Adlakha, 2017), analyze the attractiveness of specific environments for activities (Hirsch et al., 2014), provide a new perspective to sense people's spatial and temporal preference in urban space (Shen and Karimi, 2016, Zhao et al., 2019).

As shown in Table 1, researchers have considered in different fields to apply the new data to the urban spatial quality. New data here shows many strong advantages, for instance, researchers apply built environment data to quantify environment quality from humanistic perspective and to gain new insights into the microscale environment details that might influence urban spatial quality, apply media data to analyze people's distribution and mood, which also indicate the urban spatial quality. As can be seen, new data provides an effective way to study urban spatial quality by accurately measuring, evaluating and defining the built environment from small-scale to large-scale. The multi-dimensional analyzing and measuring are also the basis for further understanding and deeper research of the city, which reveal the dynamic evolution and structural rule behind the complex urban problems through a real deeper perspective and a broader vision. The application of new data is a feasible direction for further multiscale urban spatial quality research.

Table 1. New data advantages and application fields in urban spatial quality

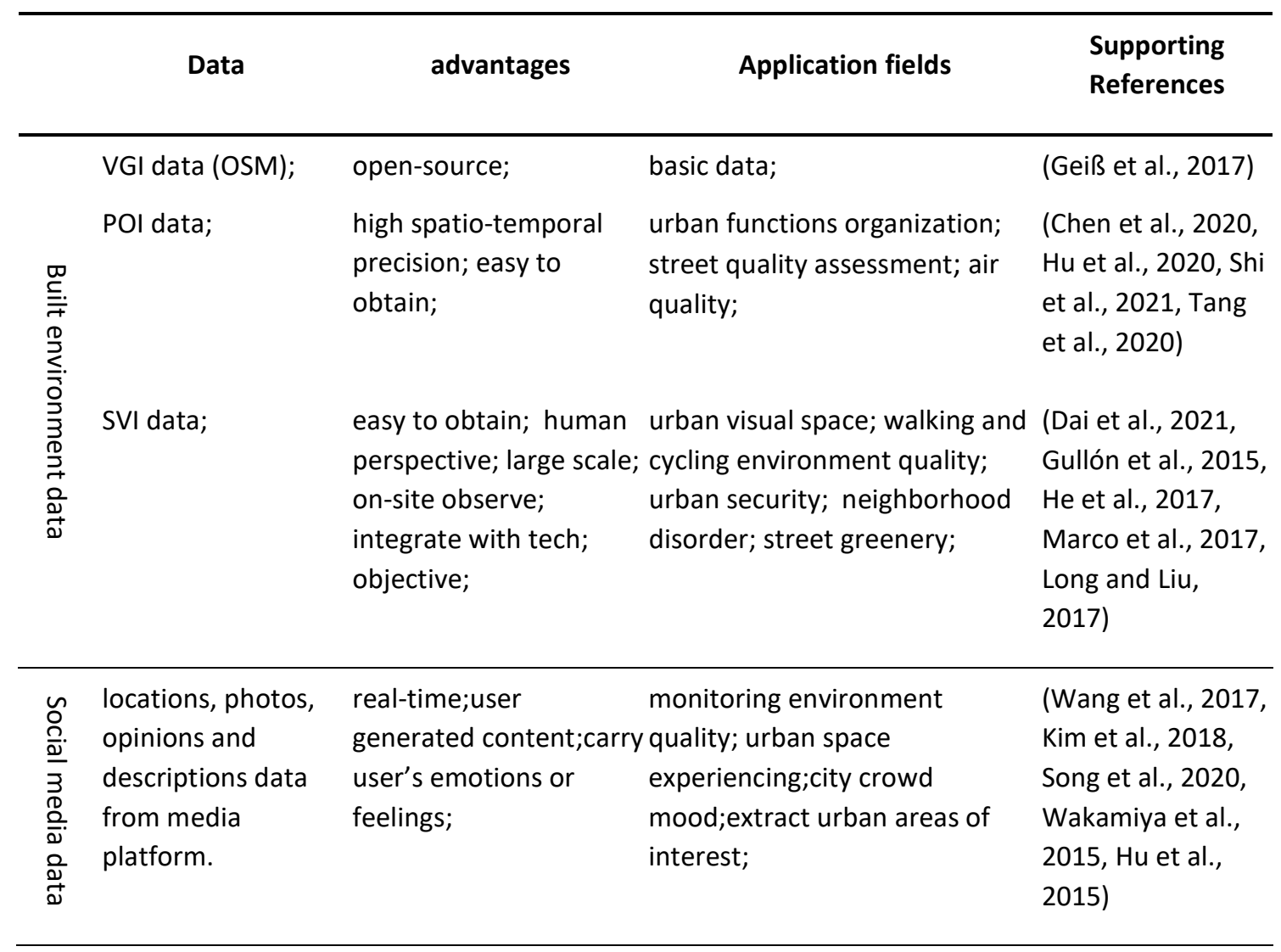




\begin{tabular}{|c|c|c|c|c|}
\hline 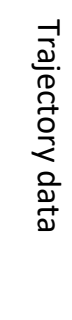 & $\begin{array}{l}\text { tracking data; } \\
\text { vehicle GPS; } \\
\text { check-in data; } \\
\text { MPD, LBS data; } \\
\text { smart card data }\end{array}$ & $\begin{array}{l}\text { geo-tagged;overall trip } \\
\text { be obtained;passive } \\
\text { group data;geo-tagged; } \\
\text { no extra equipment; } \\
\text { consistency; }\end{array}$ & $\begin{array}{l}\text { physical activity; urban hots } \\
\text { pot detection; urban public } \\
\text { green space; urban function } \\
\text { connectivity; air pollution in } \\
\text { urban; urban functions }\end{array}$ & $\begin{array}{l}\text { (Hirsch et al., } \\
\text { 2014, Zhao et al., } \\
\text { 2019, Zheng et al., } \\
\text { 2019, Shen and } \\
\text { Karimi, 2016, Dias } \\
\text { and Tchepel, 2014, } \\
\text { Wang et al., 2021) }\end{array}$ \\
\hline
\end{tabular}

Source: Based on the internet search

\section{New technology environment support for multi-dimensional spatial quality detecting and feedback}

Caused by the inevitable emergence of various measurement tools and instruments, the highly accelerated calculation and improvement on information processing capabilities have greatly enriched the type and scope of data. New technology is changing the way people understand and perceive the built environment, offering key opportunities for urban planning, urban design, and architecture (Hollander et al., 2018). The new technologies include deep learning, virtual reality, eye tracking, physiological sensors, etc.

Deep learning is an important topic in artificial intelligence. Deep learning image semantic segmentation can rank street view images to regions and categories which is widely used in street view image analysis. The tools can efficiently identify construction elements such as sky, plants, buildings, and greenery in the human perspective view (Badrinarayanan et al., 2017). Furthermore, a series of image recognition tools have been invented, constantly updated to recognize images. These training models recognize the semantic features of the sample model through training on small sample data, then applied in the largescale automatic measurement of human-scale spatial elements in the built environment. (Zhang et al., 2018, Dubey et al., 2016, Ki and Lee, 2021, Naik et al., 2014).

Virtual reality (VR) has been proposed for various purposes such as design studies, presentation, simulation, and communication in the computer-aided architectural design (Fukuda et al., 2021). VR construct virtual worlds by using three-dimensional computer graphics objects and provide interactive movies via rendering processing. Virtual reality technology has been used in urban design project development, external evaluation, and public participation in assisting decision-making (Portman et al., 2015, Smith, 2015).

Eye tracking enables us to record unconscious eye movement, enriches understanding of how people respond to the built environment (Hollander et al., 2018), and provides new data on 'unseen' experiences. An increasing popularity of eye tracking methodology for investigating research questions related to spatial cognition led by recent technological developments is flourishing (Kiefer et al., 2017), to explore the ways that people perceive landscapes, focusing on fixations, saccade amplification, blink rates, gaze paths and built environment (Hollander et al., 2020, Lisińska-Kuśnierz and Krupa, 2020, Simpson et al., 2019).

Physiological sensors are composed of portable and wearable electrocardiographic sensors, brain electrical sensors, skin electrical sensors, and skin temperature sensors, etc (Mavros et al., 2016). The wearable physiological sensor technology fused with GPS spatial location data can generate a geo-tagged spatial trajectory and provide important support for urban spatial behavior research based on human perspective perception signal data (Aspinall et al., 2015, Huang et al., 2019). 
As shown in Table 2, the effective application of deep learning, virtual reality technology, eye tracking, and physiological sensors has been confirmed by many researchers. New technologies in different application fields show great potential in urban detecting, deep learning provides strong support for indepth analysis of the complex built environment, and more accurate record people's behavior and preception, with the aid of artificial intelligence, virtual reality provides an immersive model that audience could participate and then feedback the design, eye tracking and physiological sensor explain how people immersed within built environment, provide more accurate behavior and perception records. With regard to new technologies applied in urban studies, the limitation of data acquisition has been greatly changed, the scope of research method has been expanded and the study efficiency has been promoted.

Table 2. New technology advantages and application fields in urban spatial quality

\begin{tabular}{|c|c|c|c|}
\hline types & advantages & Application fields & Supporting References \\
\hline $\begin{array}{l}\text { Deep } \\
\text { learning }\end{array}$ & $\begin{array}{l}\text { large-scale; automatic; } \\
\text { objective; }\end{array}$ & $\begin{array}{l}\text { urban elements identify; urban } \\
\text { image recognizing; urban spatial } \\
\text { quality; smart city; urban } \\
\text { attractiveness; urban facade } \\
\text { color; }\end{array}$ & $\begin{array}{l}\text { (Badrinarayanan et al., } \\
\text { 2017, Dubey et al., 2016, } \\
\text { Ki and Lee, 2021, Naik et } \\
\text { al., 2014, Zhong et al., } \\
\text { 2021) }\end{array}$ \\
\hline $\begin{array}{l}\text { Virtual } \\
\text { reality }\end{array}$ & $\begin{array}{l}\text { expending visual sense; } \\
\text { feedback and } \\
\text { participation; immersive; }\end{array}$ & $\begin{array}{l}\text { urban design; environment } \\
\text { planning; participatory design, } \\
\text { preference and behavior; }\end{array}$ & $\begin{array}{l}\text { (Fukuda et al., 2021, } \\
\text { Portman et al., 2015, } \\
\text { Smith, 2015) }\end{array}$ \\
\hline $\begin{array}{l}\text { Eye } \\
\text { tracking }\end{array}$ & $\begin{array}{l}\text { real-time rendering; } \\
\text { immersive }\end{array}$ & $\begin{array}{l}\text { street facades quality; spatial } \\
\text { cognition; urban spatial } \\
\text { visualization; visual engagement } \\
\text { in street; }\end{array}$ & $\begin{array}{l}\text { (Hollander et al., 2021, } \\
\text { Kiefer et al., 2017, } \\
\text { Lisińska-Kuśnierz and } \\
\text { Krupa, 2020, Simpson et } \\
\text { al., 2019) }\end{array}$ \\
\hline $\begin{array}{l}\text { Physio- } \\
\text { logical } \\
\text { sensor }\end{array}$ & $\begin{array}{l}\text { portable; real-time } \\
\text { rendering; intensive; }\end{array}$ & $\begin{array}{l}\text { spatial cognition; urban } \\
\text { behavior; physiological effect of } \\
\text { urban environment; }\end{array}$ & $\begin{array}{l}\text { (Mavros et al., 2016, } \\
\text { Aspinall et al., 2015, } \\
\text { Huang et al., 2019) }\end{array}$ \\
\hline
\end{tabular}

Source: Based on the internet search

\section{Urban spatial quality development on smart city platform}

In the context of big data, the construction of smart city platform is an inevitable urban development trend. The measurement and evaluation of urban spatial quality based on the smart city platform is necessary for urban development, but there still exist incompletion and imperfection (Fang et al., 2021). Also, the standards for judging the quality of urban space have developed with the construction of smart city, here we envision how response to this trend with a five process framework, as shown in Figure 1. 


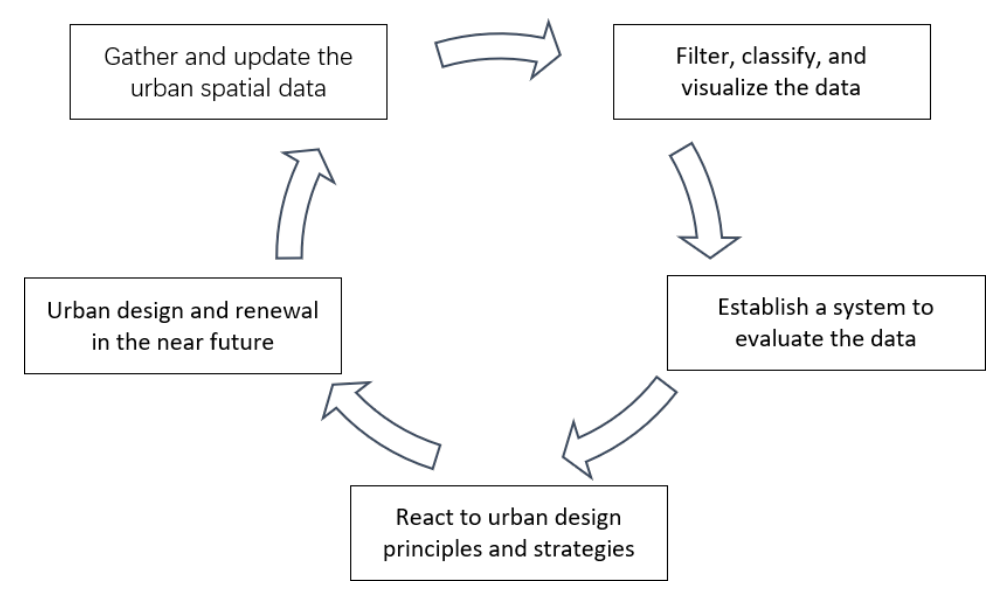

Figure 1: Five processes response to smart city. Source: by author

1)Gather and update the urban spatial data. Collecting the data in open platform, urban sensor equipment, network platform, and other scattered information sources is the foundation of the process.

2)Filter, classify, and visualize the data. Considering the multi-source and muti-type of unban spatial data, it is necessary to reprocess all kinds of data and present them vividly. And it provides smart city with basic capacity such as storage, computing, and sharing.

3)Establish a system to evaluate the data. New technologies and new data support the establishment of the evaluation system for evaluating urban quality from multi-dimensions. Based on the evaluation system, the urban quality could be quantified, and the spatial quality judged in an objective way comprehendingly. In addition, whether the system can meet the basis of city quality and reflect its effectiveness is also an important process to judge.

4)React to urban design principles and strategies. New technologies continuously influence the concept of physical space, people's behaviours and activities have undergone great changes and new demands for urban space have been put forward. Urban spatial design should be considered for networking, becoming a participant in the digital environment, and a component of the smart city network. Sustainability, networking, and flexibility are all urban spatial characteristics to be considered.

5)Urban design and renewal in the near future. Designers need to enhance urban design and urban spatial quality in a more objective, sustainable, and human-oriented way.

These five processes from macro perspective simply show the possibilities that new data and new technologies in the cycle process could bring. Although the construction of smart city platform in many regions is still in its infancy, the characteristics of new data and new technologies indicate that the measurement and improvement of urban space quality will undergo tremendous development, and the construction of urban environment will take a new step.

\section{Conclusion}

Under the environment of new data and new technology, many new urban data analysis methods and urban design basis have been produced to expand people's understanding of urban space. Based on the smart city platform, the development direction of urban space quality has changed, new technologies and new data have given us new in-depth possibilities and new directions in research methods. Futher more, the combination of new methods and new data provides a new way of thinking about complex scientific issues in urban space, which adapt to the development trend of the smart city, to find more effective urban design methods. What we need to focus is not the new technologies and data themselves, but the impact on urban spatial design. In which way will our methods of designing evolve? How to 
connect the concept of the network with urban design? How to uncover the potential of urban spatial space in future digital world consciously? How to use technology and the digital Internet based on the smart city platform to enhance the value of design? These are the problems we will face.

\section{Acknowledgements}

This paper was funded by the National Natural Science Foundation (Youth Fund) of China (Grant No.52008128).

\section{References}

Adlakha, D. (2017). Quantifying the modern city: emerging technologies and big data for active living research. Frontiers in public health, 5, p105.

Aspinall, P., Mavros, P., Coyne, R. \& Roe, J. (2015). The urban brain: analysing outdoor physical activity with mobile EEG. British journal of sports medicine, 49, p272-276.

Badrinarayanan, V., Kendall, A. \& Cipolla, R. (2017). Segnet: A deep convolutional encoder-decoder architecture for image segmentation. IEEE transactions on pattern analysis and machine intelligence, 39, p2481-2495.

Cervero, R. \& Kockelman, K. (1997). Travel demand and the 3Ds: Density, diversity, and design. Transportation research part D: Transport and environment, 2, p199-219.

Chen, Y., Chen, X., Liu, Z. \& Li, X. (2020). Understanding the spatial organization of urban functions based on co-location patterns mining: A comparative analysis for 25 Chinese cities. Cities, 97, p102563.

Clifton, K. J., Smith, A. D. L. \& Rodriguez, D. (2007). The development and testing of an audit for the pedestrian environment. Landscape and Urban Planning, 80, p95-110.

Dai, L., Zheng, C., Dong, Z., Yao, Y., Wang, R., Zhang, X., Ren, S., Zhang, J., Song, X. \& Guan, Q. (2021). Analyzing the correlation between visual space and residents' psychology in Wuhan, China using street-view images and deep-learning technique. City and Environment Interactions, 11, p100069.

Dias, D. \& Tchepel, O. (2014). Modelling of human exposure to air pollution in the urban environment: a GPS-based approach. Environmental Science and Pollution Research, 21, p3558-3571.

Dubey, A., Naik, N., Parikh, D., Raskar, R. \& Hidalgo, C. A. (2016). Deep learning the city: Quantifying urban perception at a global scale. European conference on computer vision. Springer, p196-212.

Ewing, R., Handy, S., Brownson, R. C., Clemente, O. \& Winston, E. (2006). Identifying and measuring urban design qualities related to walkability. Journal of Physical Activity and Health, 3, pS223-S240.

Fang, Y., Shan, Z. \& Wang, W. (2021). Modeling and Key Technologies of a Data-Driven Smart City System. IEEE Access, 9, p91244-91258.

Fukuda, T., Novak, M., Fujii, H. \& Pencreach, Y. (2021). Virtual reality rendering methods for training deep learning, analysing landscapes, and preventing virtual reality sickness. International Journal of Architectural Computing, 19, p190-207.

Geiß, C., Schauß, A., Riedlinger, T., Dech, S., Zelaya, C., Guzmán, N., Hube, M. A., Arsanjani, J. J. \& Taubenböck, H. (2017). Joint use of remote sensing data and volunteered geographic information for exposure estimation: evidence from Valparaíso, Chile. Natural Hazards, 86, p81-105. 
Gullón, P., Badland, H. M., Alfayate, S., Bilal, U., Escobar, F., Cebrecos, A., Diez, J. \& Franco, M. (2015). Assessing walking and cycling environments in the streets of Madrid: comparing on-field and virtual audits. Journal of urban health, 92, p923-939.

Haklay, M. (2010). How good is volunteered geographical information? A comparative study of OpenStreetMap and Ordnance Survey datasets. Environment and planning B: Planning and design, 37, p682-703.

He, L., Páez, A. \& Liu, D. (2017). Built environment and violent crime: An environmental audit approach using Google Street View. Computers, Environment and Urban Systems, 66, p83-95.

Hirsch, J. A., James, P., Robinson, J. R., Eastman, K. M., Conley, K. D., Evenson, K. R. \& Laden, F. (2014). Using MapMyFitness to place physical activity into neighborhood context. Frontiers in public health, 2, p19.

Hollander, J. B., Purdy, A., Wiley, A., Foster, V., Jacob, R. J., Taylor, H. A. \& Brunyé, T. T. (2018). Seeing the city: Using eye-tracking technology to explore cognitive responses to the built environment. Journal of Urbanism: International Research on Placemaking and Urban Sustainability.

Hollander, J. B., Sussman, A., Lowitt, P., Angus, N. \& Situ, M. (2021). Eye-tracking emulation software: a promising urban design tool. Architectural Science Review, p1-11.

Hollander, J. B., Sussman, A., Purdy Levering, A. \& Foster-Karim, C. (2020). Using eye-tracking to understand human responses to traditional neighborhood designs. Planning Practice \& Research, 35, p485-509.

Hu, F., Liu, W., Lu, J., Song, C., Meng, Y., Wang, J. \& Xing, H. (2020). Urban function as a new perspective for adaptive street quality assessment. Sustainability, 12, p1296.

Hu, S., Gao, S., Wu, L., Xu, Y., Zhang, Z., Cui, H. \& Gong, X. (2021). Urban function classification at road segment level using taxi trajectory data: A graph convolutional neural network approach. Computers, Environment and Urban Systems, 87, p101619.

Hu, Y., Gao, S., Janowicz, K., Yu, B., Li, W. \& Prasad, S. (2015). Extracting and understanding urban areas of interest using geotagged photos. Computers, Environment and Urban Systems, 54, p240-254.

Huang, S.-C. L., Chiang, N. C., Kuo, N.-F. \& Chen, Y.-J. (2019). An exploratory approach for using EEG to examine person-environment interaction. Landscape Research, 44, p702-715.

Ki, D. \& Lee, S. (2021). Analyzing the effects of Green View Index of neighborhood streets on walking time using Google Street View and deep learning. Landscape and Urban Planning, 205, p103920.

Kiefer, P., Giannopoulos, I., Raubal, M. \& Duchowski, A. (2017). Eye tracking for spatial research: Cognition, computation, challenges. Spatial Cognition \& Computation, 17, p1-19.

Kim, H. J., Chae, B. K. \& Park, S. B. (2018). Exploring public space through social media: an exploratory case study on the High Line New York City. Urban Design International, 23, p69-85.

Lisińska-Kuśnierz, M. \& Krupa, M. (2020). Suitability of eye tracking in assessing the visual perception of architecture-A case study concerning selected projects located in cologne. Buildings, 10, p20.

Long, Y. \& Liu, L. (2017). How green are the streets? An analysis for central areas of Chinese cities using Tencent Street View. PloS one, 12, pe0171110.

Marco, M., Gracia, E., Martín-Fernández, M. \& López-Quílez, A. (2017). Validation of a Google Street View-based neighborhood disorder observational scale. Journal of urban health: bulletin of the New York Academy of Medicine, 94, p190. 
Mavros, P., Austwick, M. Z. \& Smith, A. H. (2016). Geo-EEG: towards the use of EEG in the study of urban behaviour. Applied Spatial Analysis and Policy, 9, p191-212.

Mehta, V. (2014). Evaluating public space. Journal of Urban design, 19, 53-88.

Millstein, R. A., Cain, K. L., Sallis, J. F., Conway, T. L., Geremia, C., Frank, L. D., Chapman, J., Van Dyck, D., Dipzinski, L. R. \& Kerr, J. (2013). Development, scoring, and reliability of the Microscale Audit of Pedestrian Streetscapes (MAPS). BMC public health, 13, p1-15.

Naik, N., Philipoom, J., Raskar, R. \& Hidalgo, C. (2014). Streetscore-predicting the perceived safety of one million streetscapes. Proceedings of the IEEE conference on computer vision and pattern recognition workshops. p779-785.

Pikora, T. J., Bull, F. C. L., Jamrozik, K., Knuiman, M., Giles-Corti, B. \& Donovan, R. J. (2002). Developing a reliable audit instrument to measure the physical environment for physical activity. American Journal of Preventive Medicine, 23, p187-194.

Portman, M. E., Natapov, A. \& Fisher-Gewirtzman, D. (2015). To go where no man has gone before: Virtual reality in architecture, landscape architecture and environmental planning. Computers, Environment and Urban Systems, 54, p376-384.

Shen, Y. \& Karimi, K. (2016). Urban function connectivity: Characterisation of functional urban streets with social media check-in data. Cities, 55, p9-21.

Shi, J., Gao, H., Cheng, H., Sun, H. \& Huang, D. (2021). Study on the exposure risk based on the PM2. 5 pollution characteristics of POls and their attractiveness to the crowd. Human and Ecological Risk Assessment: An International Journal, 27, p980-998.

Simpson, J., Thwaites, K. \& Freeth, M. (2019). Understanding Visual Engagement with Urban Street Edges along Non-Pedestrianised and Pedestrianised Streets Using Mobile Eye-Tracking. Sustainability, $11, \mathrm{p} 4251$.

Smith, J. W. (2015). Immersive virtual environment technology to supplement environmental perception, preference and behavior research: a review with applications. International journal of environmental research and public health, 12, p11486-11505.

Song, Y., Fernandez, J. \& Wang, T. (2020). Understanding perceived site qualities and experiences of urban public spaces: A case study of social media reviews in Bryant park, New York city. Sustainability, 12, p8036.

Tang, Z., Ye, Y., Jiang, Z., Fu, C., Huang, R. \& Yao, D. (2020). A data-informed analytical approach to human-scale greenway planning: Integrating multi-sourced urban data with machine learning algorithms. Urban Forestry \& Urban Greening, 56, p126871.

Van Kamp, I., Leidelmeijer, K., Marsman, G. \& De Hollander, A. (2003). Urban environmental quality and human well-being: Towards a conceptual framework and demarcation of concepts; a literature study. Landscape and urban planning, 65, p5-18.

Wakamiya, S., Belouaer, L., Brosset, D., Lee, R., Kawai, Y., Sumiya, K. \& Claramunt, C. (2015). Measuring crowd mood in city space through twitter. International Symposium on Web and Wireless Geographical Information Systems. Springer, p37-49.

Wang, Z., Ke, L., Cui, X., Yin, Q., Liao, L., Gao, L. \& Wang, Z. (2017). Monitoring environmental quality by sniffing social media. Sustainability, 9, p85.

Wang, Z., Liu, H., Zhu, Y., Zhang, Y., Basiri, A., Büttner, B., Gao, X. \& Cao, M. (2021). Identifying Urban Functional Areas and Their Dynamic Changes in Beijing: Using Multiyear Transit Smart Card Data. Journal of Urban Planning and Development, 147, p04021002. 
Wen, W. \& Wei, W. (2016). Social media as research instrument for urban planning and design. 2016 Eighth International Conference on Measuring Technology and Mechatronics Automation (ICMTMA). IEEE, p614-616.

Yang, Y., Hsu, J.-H., Löfgren, K. \& Cho, W. (2021). Cross-platform comparison of framed topics in Twitter and Weibo: machine learning approaches to social media text mining. Social Network Analysis and Mining, 11, p1-18.

Zhang, F., Zhou, B., Liu, L., Liu, Y., Fung, H. H., Lin, H. \& Ratti, C. (2018). Measuring human perceptions of a large-scale urban region using machine learning. Landscape and Urban Planning, 180, p148-160.

Zhang, L., Pei, T., Chen, Y., Song, C. \& Liu, X. (2019). A review of urban environmental assessment based on street view images. J. Geo-Inf. Sci, 21, p46-58.

Zhao, P., Liu, X., Shen, J. \& Chen, M. (2019). A network distance and graph-partitioning-based clustering method for improving the accuracy of urban hotspot detection. Geocarto International, 34, p293315 .

Zheng, Q., Zhao, X. \& Jin, M. (2019). Research on urban public green space planning based on taxi data: A case study on three districts of Shenzhen, China. Sustainability, 11, p1132.

Zhong, T., Ye, C., Wang, Z., Tang, G., Zhang, W. \& Ye, Y. (2021). City-Scale Mapping of Urban Façade Color Using Street-View Imagery. Remote Sensing, 13, p1591. 